Case Report

\title{
A Novel Technique for Managing Pancreaticojejunal Anastomotic Leak after Pancreaticoduodenectomy
}

\author{
Tufan Egeli, Tarkan Unek, Mucahit Ozbilgin, Mustafa Goztok, and Ibrahim Astarcıglu \\ HPB Surgery and Liver Transplantation Unit, Department of General Surgery, School of Medicine, Dokuz Eylul University, \\ Inciralti, 35340 İzmir, Turkey \\ Correspondence should be addressed to Tufan Egeli; tufanegeli@gmail.com
}

Received 24 January 2016; Accepted 24 May 2016

Academic Editor: Nicholas N. Nissen

Copyright (C) 2016 Tufan Egeli et al. This is an open access article distributed under the Creative Commons Attribution License, which permits unrestricted use, distribution, and reproduction in any medium, provided the original work is properly cited.

Pancreaticoduodenectomy (Whipple's procedure) remains the only definitive treatment option for tumors of the periampullary region. The most common and life-threatening complications following the procedure are pancreatic anastomotic leakage and subsequent fistula formation. When these complications occur, treatment strategy depends on the severity of anastomotic leakage, with patients with severe leakages requiring reoperation. The optimal surgical method used for reoperation is selected from among different options such as wide drainage, definitive demolition of the pancreaticojejunal anastomosis and performing a new one, or completion pancreatectomy. Here we present a novel, simple technique to manage severe pancreatic leakage via ligamentum teres hepatis patch.

\section{Introduction}

Pancreaticoduodenectomy (Whipple's procedure) has become a routine procedure for malignant periampullary tumors as well as benign disorders including chronic pancreatitis, diverticula, or large adenomas of the periampullary region. Resection itself is no longer problematic, although the reconstruction of pancreatic remnant is still challenging. Whereas mortality rate has been reduced to less than $5 \%$ in experienced centers, morbidity remains as high as 30 to $50 \%$ even in large series [1]. The most important complications related to pancreatic remnant are pancreaticojejunal anastomotic leakage (PJAL) and subsequent pancreatic fistula $[1,2]$. In the case of severe PJAL, reoperation is crucial and it depends on the clinical status of a patient [3]. Pancreaticogastrostomy, repeat pancreaticojejunostomy, or total pancreatectomy may become necessary for its management. Here we present a simple and efficient technique using ligamentum teres hepatis (LTH) patch for the treatment of PJAL.

\section{Case and Technique}

A 72-year-old male patient underwent pancreaticoduodenectomy for carcinoma of pancreatic head in our clinic. During the operative evaluation, pancreatic texture was soft; the diameter of the Wirsung duct was 2 millimeters. After resection, we performed an end-to-side, duct-to-mucosa pancreaticojejunal anastomosis with $6 / 0$ polyglactin sutures in order to manage the pancreatic remnant. We started intravenous somatostatin infusion ( $6 \mathrm{mg} / 24$ hours) perioperatively to avoid subsequent pancreatic fistula formation. Histopathological examination revealed that the neoplastic mass was an adenocarcinoma (pT2N1). During the first 9 days after the surgery the patient was stable and there were no signs of PJAL. However, at day 10 postoperatively the patient developed continuous fever, hypotension, tachycardia, abdominal distention, signs of peritoneal irritation, and leukocytosis. The content of abdominal drainage was pure biliary. An abdominopelvic ultrasonography showed diffuse intra-abdominal fluid collection. All findings were consistent with abdominal sepsis secondary to severe PJAL; hence, we decided a reoperation. During the exploration at the surgery, the abdominal cavity was full of bile. After carrying out effective abdominal irrigation and debridement, we checked all anastomotic suture lines for leakage. A 4millimeter dehiscence and leakage line was detected at the right side of the pancreaticojejunal anastomosis (Figure 1). Both the pancreatic remnant and jejunal limb tissue were 


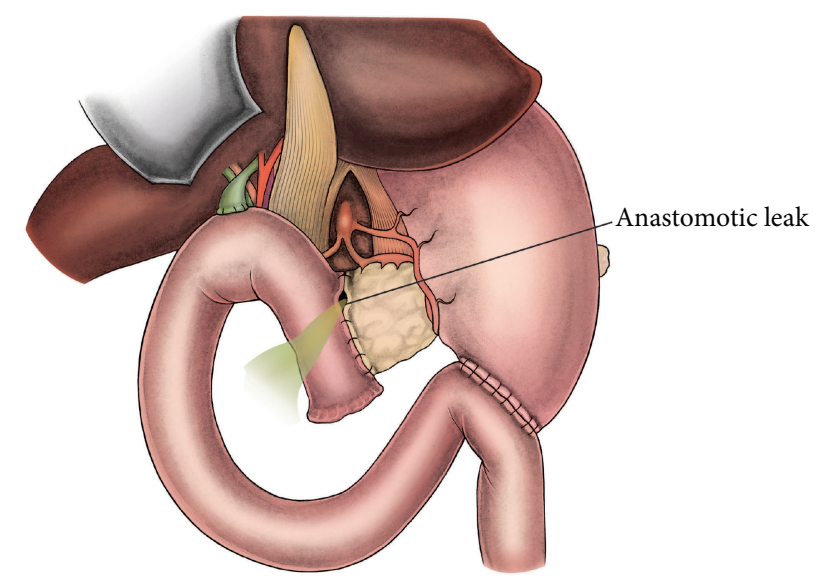

FIGURE 1: Anastomotic dehiscence and leakage from the right side of the pancreaticojejunal anastomosis.

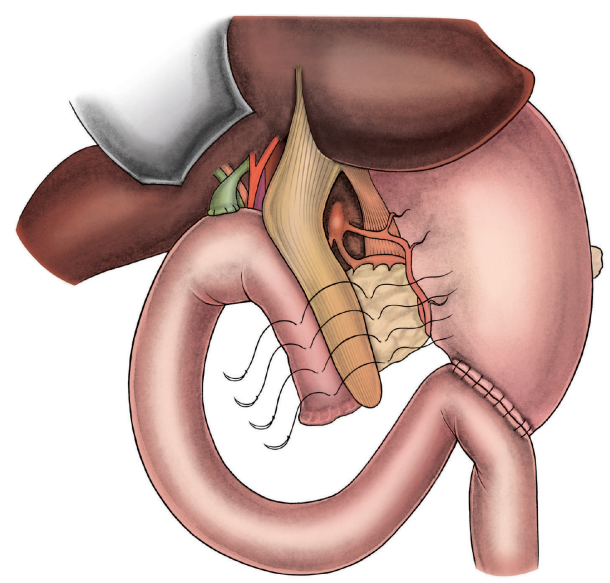

FIGURE 2: The mobilized ligamentum teres hepatis is placed onto the dehiscence side as a patch and fixed with interrupted sutures that were put on both pancreas and jejunum.

observed to be inflammatory and edematous. Therefore, we deemed these tissues unsuitable for suturing securely, and we decided to use ligamentum teres hepatis (LTH) as a patch for reparation. Then we mobilized LTH and placed it onto the site of dehiscence and the upper part of the pancreaticojejunal anastomosis. LTH patch was fixed on both the pancreatic remnant and jejunal limb with interrupted polyglactin sutures, as shown in the illustrations (Figures 2 and 3). After achieving hemostasis and performing a sponge count, low negative pressure drains were placed in both peripancreatic areas. Finally, the pelvis and then the abdomen were closed. During the follow-up after surgery, no postoperative complications or signs of pancreatic leakage or fistula were observed. The patient was discharged with full recovery at day 9 postoperatively.

\section{Discussion}

Pancreaticojejunal anastomotic leak rate has been reported to occur in $6-24 \%$ of patients after pancreaticoduodenectomy

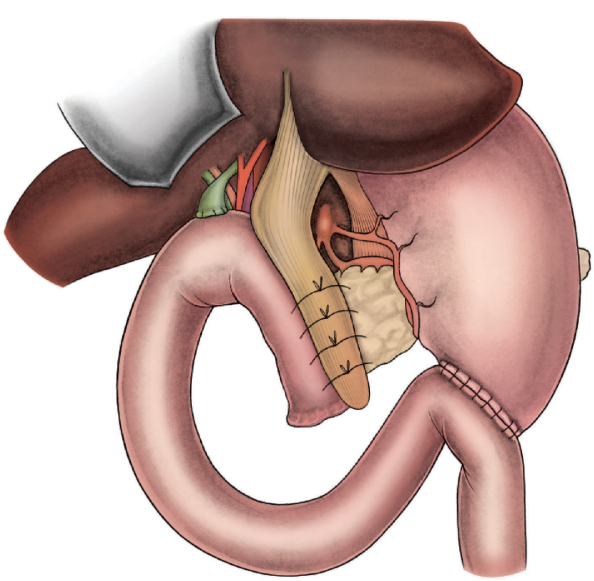

FIGURE 3: Gently ligated sutures serve to keep the teres hepatis patch in place.

[4-6], and it is associated with a mortality rate of $20 \%$ to $80 \%$ [7]. Conservative treatment usually yields excellent outcomes in mild PJAL [4-6]. However, in severe PJAL and particularly in the case of anastomotic dehiscence, reoperation becomes inevitable because it constitutes the primary cause of early postoperative mortality due to abdominal sepsis $[3,8]$. In such cases, a surgeon should consider the extent of dehiscence, the clinical status of the patient, and the vitality of the pancreatic remnant to decide the best surgical management. Depending on the severity of leakage, simple wide drainage, creating a new pancreaticojejunal anastomosis, or even completion pancreatectomy can be the treatment of choice [1-3].

In the case of sufficient anastomosis but a small anastomotic leakage, irrigation of the leakage site and insertion of additional drains into the lesser sac is an appropriate approach. In the case of anastomotic disruption or subtotal dehiscence, however, surgical repair of the anastomosis should generally not be attempted because blood supply to that area is often not adequate and the inflammatory tissue may not be securely sutured $[1,9]$. On the other hand, resecting a few centimeters of the pancreatic remnant and performing a new pancreaticojejunal anastomosis is a highrisk procedure with the possibility of a new anastomotic failure with persistent leakage and sepsis [2]. Some authors suggested salvage pancreaticogastrostomy as an alternative method to manage PJAL [10] but the experience with this technique seems limited in the literature. In cases with severe PJAL, completion pancreatectomy including splenectomy is still the only life-saving option, which should be performed before septic shock develops [11-14]. However, completion pancreatectomy should be limited to clinical circumstances in which there is no alternative because it is well known that more extensive interventions are hazardous and associated with higher morbidity and mortality [2-4].

The usage of mobilized ligamentum falciform hepatis for protection of gastroduodenal artery stump during pancreaticoduodenectomy has been defined previously [15]. In that method, the purpose is to minimize the risk for 
pseudoaneurysm formation at the site of the gastroduodenal artery stump in the event of pancreatic anastomotic leak. On the other hand, Hackert et al. described a successful technique of teres hepatis ligament patch as an additional supracapsular sealing structure for postoperative pancreatic fistula prevention after tumor enucleation from pancreas [16]. In a similar manner, Wu et al. reported usage of ligamentum teres hepatis as a patch to cover the pancreatic stump in order to avoid pancreatic fistula [17]. During the operation, we also recalled Graham's Technique for the treatment of perforated ulcers [18], and hence we decided to synthesize these techniques. So, we developed a novel method that was outlined above. Fortunately, it worked successfully and our patient was discharged with full recovery and without any complication. As a result, we suggest that this simple novel technique may be an alternative strategy as a less aggressive, organ preserving, and effective method when reoperation is necessary for PJAL after pancreaticoduodenectomy.

\section{Competing Interests}

The authors declare no conflict of interests.

\section{References}

[1] A. Kleespies, M. Albertsmeier, F. Obeidat, H. Seeliger, K.-W. Jauch, and C. J. Bruns, "The challenge of pancreatic anastomosis," Langenbeck's Archives of Surgery, vol. 393, no. 4, pp. 459-471, 2008.

[2] S. Crippa, R. Salvia, M. Falconi, G. Butturini, L. Landoni, and C. Bassi, "Anastomotic leakage in pancreatic surgery," $H P B$, vol. 9, no. 1, pp. 8-15, 2007.

[3] S. M. M. de Castro, O. R. C. Busch, and D. J. Gouma, "Management of bleeding and leakage after pancreatic surgery," Best Practice and Research: Clinical Gastroenterology, vol. 18, no. 5, pp. 847-864, 2004.

[4] G. Veillette, I. Dominguez, C. Ferrone et al., "Implications and management of pancreatic fistulas following pancreaticoduodenectomy: The Massachusetts General Hospital experience," Archives of Surgery, vol. 143, no. 5, pp. 476-481, 2008.

[5] C. Bassi, C. Dervenis, G. Butturini et al., "Postoperative pancreatic fistula: an international study group (ISGPF) definition," Surgery, vol. 138, no. 1, pp. 8-13, 2005.

[6] C. J. Yeo, J. L. Cameron, K. D. Lillemoe et al., "Does prophylactic octreotide decrease the rates of pancreatic fistula and other complications after pancreaticoduodenectomy? Results of a prospective randomized placebo-controlled trial," Annals of Surgery, vol. 232, no. 3, pp. 419-429, 2000.

[7] S. M. M. De Castro, O. R. C. Busch, T. M. van Gulik, H. Obertop, and D. J. Gouma, "Incidence and management of pancreatic leakage after pancreatoduodenectomy," British Journal of Surgery, vol. 92, no. 9, pp. 1117-1123, 2005.

[8] P. O. Berberat, H. Friess, J. Kleeff, W. Uhl, and M. W. Büchler, "Prevention and treatment of complications in pancreatic cancer surgery," Digestive Surgery, vol. 16, no. 4, pp. 327-336, 1999.

[9] H. G. Beger, F. Gansauge, M. Schwarz, and B. Poch, "Pancreatic head resection: the risk for local and systemic complications in 1315 patients-a monoinstitutional experience," American Journal of Surgery, vol. 194, no. 4, pp. S16-S19, 2007.
[10] S. Govil, "Salvage pancreaticogastrostomy for pancreatic fistulae after pancreaticoduodenectomy," Indian Journal of Gastroenterology, vol. 31, no. 5, pp. 263-266, 2012.

[11] M. I. van Berge Henegouwen, T. M. van Gulik, L. T. DeWit et al., "Delayed gastric emptying after standard pancreaticoduodenectomy versus pylorus-preserving pancreaticoduodenectomy: an analysis of 200 consecutive patients," Journal of the American College of Surgeons, vol. 185, no. 4, pp. 373-379, 1997.

[12] D. R. Farley, G. Schwall, and M. Trede, "Completion pancreatectomy for surgical complications after pancreaticoduodenectomy," British Journal of Surgery, vol. 83, no. 2, pp. 176-179, 1996.

[13] J. J. Cullen, M. G. Sarr, and D. M. Ilstrup, "Pancreatic anastomotic leak after pancreaticoduodenectomy: incidence, significance, and management," The American Journal of Surgery, vol. 168, no. 4, pp. 295-298, 1994.

[14] C. D. Smith, M. G. Sarr, and J. A. vanHeerden, "Completion pancreatectomy following pancreaticoduodenectomy: clinical experience," World Journal of Surgery, vol. 16, no. 3, pp. 521-524, 1992.

[15] D. B. Evans, K. K. Christians, and D. W. Foley, "Pancreaticoduodenectomy (Whipple Operation) and total pancreatectomy for cancer," in Mastery of Surgery, J. E. Fischer, D. B. Jones, F. B. Pomposelli, and G. R. Upchurch, Eds., p. 1460, Wolters Kluwer/Lippincott Williams \& Wilkins, 6th edition, 2012.

[16] T. Hackert, V. J. Lozanovski, J. Werner, M. W. Büchler, and P. Schemmer, "Teres hepatis ligament flap plasty to prevent pancreatic fistula after tumor enucleation," Journal of the American College of Surgeons, vol. 217, no. 4, pp. e29-e34, 2013.

[17] C.-T. Wu, W.-Y. Xu, L. Liu et al., "Ligamentum teres hepatis patch enhances the healing of pancreatic fistula after distal pancreatectomy," Hepatobiliary and Pancreatic Diseases International, vol. 12, no. 6, pp. 651-655, 2013.

[18] R. Graham, "The treatment of perforated duodenal ulcers," Surgery, Gynecology \& Obstetrics, vol. 64, pp. 235-238, 1937. 


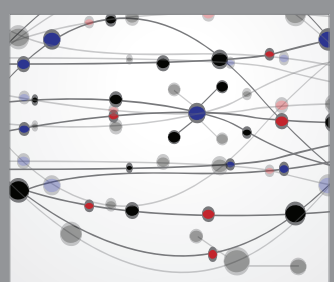

The Scientific World Journal
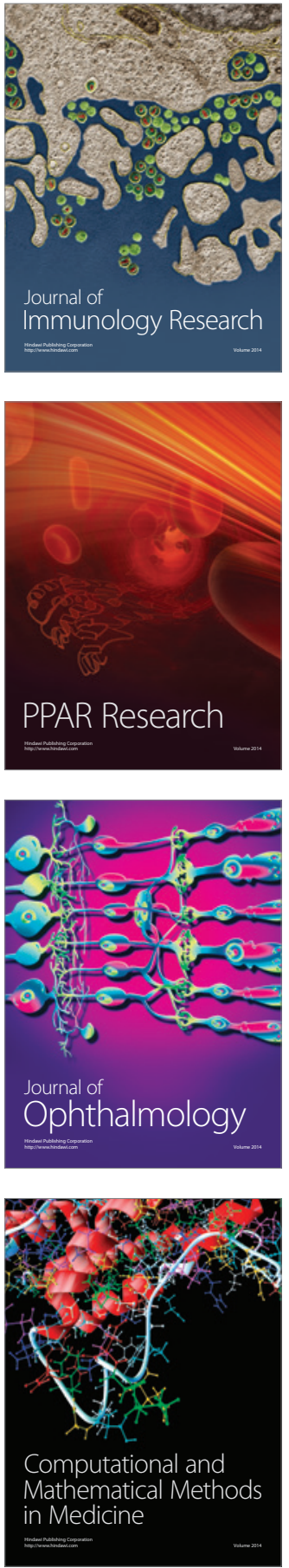

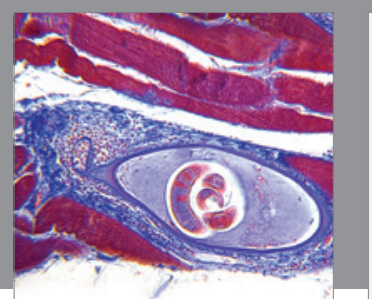

Gastroenterology Research and Practice

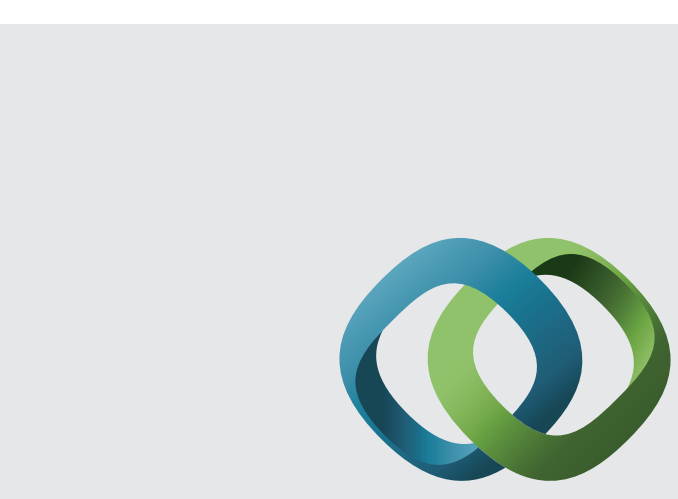

\section{Hindawi}

Submit your manuscripts at

http://www.hindawi.com
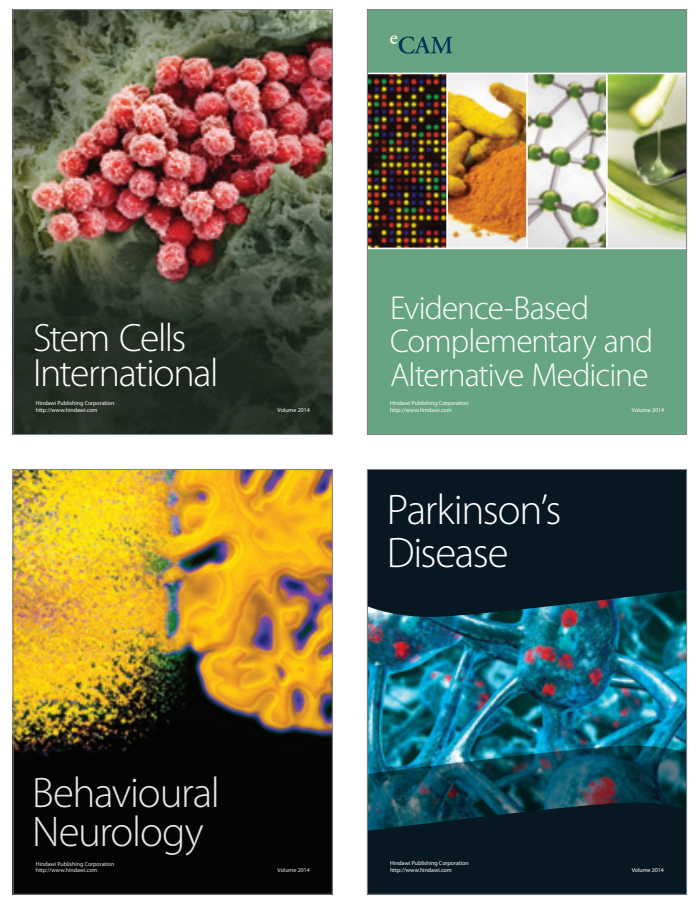
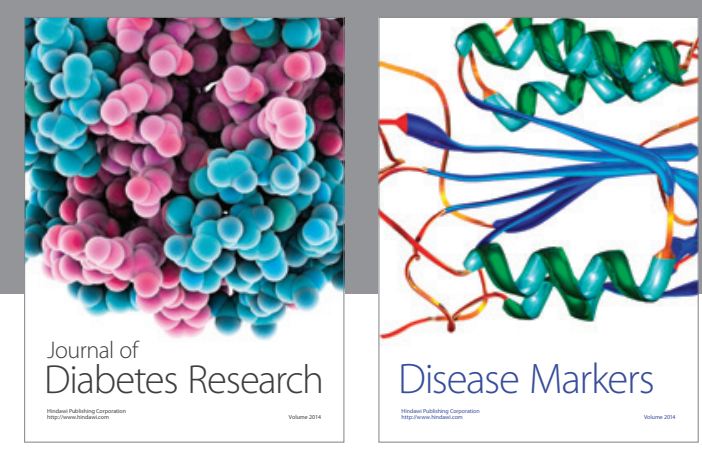

Disease Markers
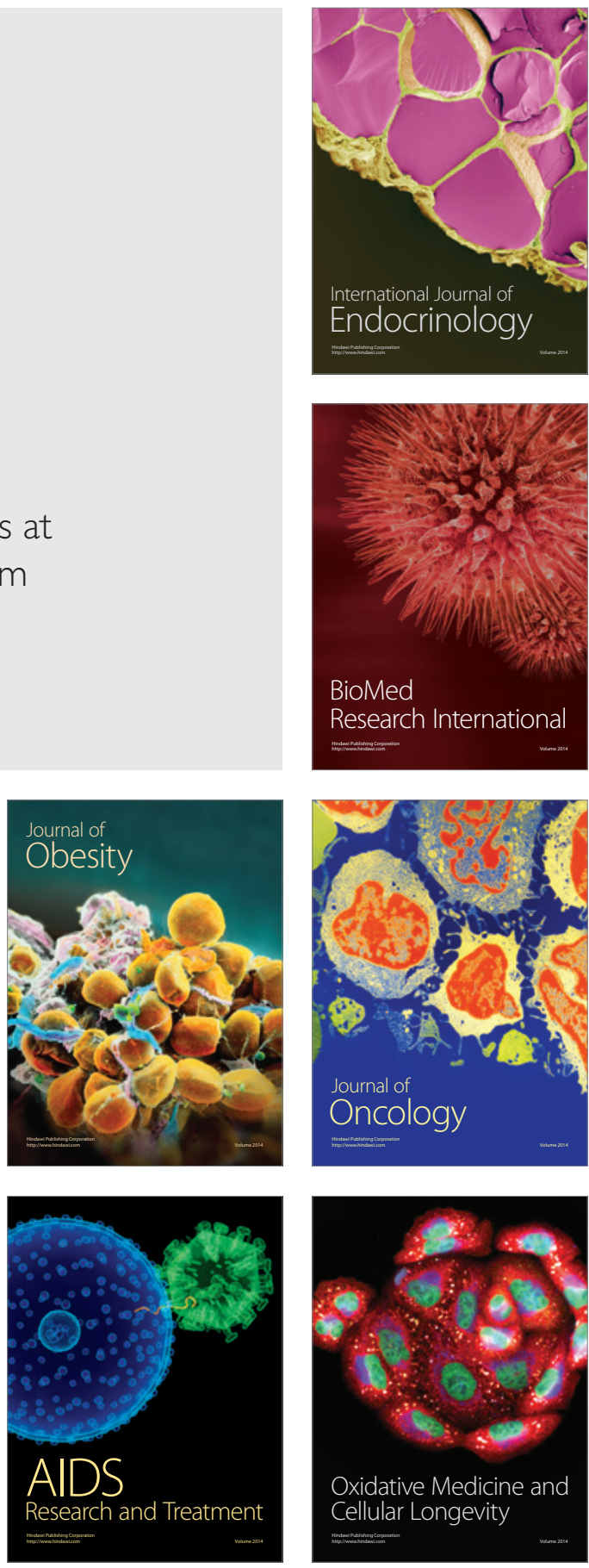